Check for updates

Cite this: RSC Adv., 2018, 8, 1451

\title{
Isolation and enantiostability of the B-chiral bis(salicylato)borate anions $\left[\mathrm{B}_{R}(\mathrm{Sal})_{2}\right]$ and $\left[\mathrm{B}_{S}(\mathrm{Sal})_{2}\right] \dagger$
}

Received 31st October 2017 Accepted 16th December 2017

DOI: 10.1039/c7ra11997f

rsc.li/rsc-advances

\author{
Lawrence W.-Y. Wong, Alex S.-F. Au Yeung, Gemma S.-S. Tam, Jack W.-H. Kan, \\ Herman H.-Y. Sung, Fu Kit Sheong, Zhenyang Lin (D) and Ian D. Williams (D)*
}

The chiral spiroborate anions $\left[\mathrm{B}_{S}(\mathrm{Sal})_{2}\right]$ and $\left[\mathrm{B}_{R}(\mathrm{Sal})_{2}\right],(R$ and $\mathrm{S}$ subscripts indicate boron stereochemistry) have been isolated as $1: 1$ quininium and $1: 2$ sparteinium salts, $[\mathrm{HQuin}]\left[\mathrm{B}_{S}(\mathrm{Sal})_{2}\right]$ and $\left[\mathrm{H}_{2} \mathrm{Spa}_{[}\left[\mathrm{B}_{R}(\mathrm{Sal})_{2}\right]_{2}\right.$ respectively, by either cation metathesis or a simple one-pot synthesis involving reaction of boric and salicylic acids with the alkaloid base. Circular dichroism (CD) spectroscopy shows that the B-based chirality is stable in polar aprotic media, such as DMF or DMSO, though labile in protic solutions. Enantiopure salts with achiral counter-cations such as $\left[\mathrm{NBu}_{4}\right]\left[\mathrm{B}_{R}(\mathrm{Sal})_{2}\right]$ may then be prepared by exchange, so these $\mathrm{B}$-chiral anions may have use in metathesis-based resolutions. Due to a site disorder the anion in $\left[\mathrm{H}_{2} \mathrm{Spa}\right]\left[\mathrm{B}_{R}(\mathrm{Sal})_{2}\right]_{2}$ is limited to $70 \%$ ee, however an enantiopure analogue $\left[\mathrm{H}_{2} \mathrm{Spa}\right]\left[\mathrm{B}_{R}(5-\mathrm{Cl}-\right.$ $\left.\mathrm{Sal}_{2}\right]_{2}$ is readily formed using 5 -chlorosalicylic acid. This also indicates a wide family of stable enantiopure $\mathrm{B}$-chiral anions may be isolated by this approach.

\section{Introduction/background}

Spiroborate anions are readily prepared by direct reaction of boric acid, chelating oxyacids, such as diols, catechols, $\alpha-$ hydroxy acids and salicylic acids, together with a suitable base. ${ }^{1,2}$ Their salts may have a wide variety of properties and potential applications. ${ }^{2}$ As analogues of commonly used $\mathrm{BF}_{4}{ }^{-}$ and $\mathrm{BPh}_{4}{ }^{-}$anions they may serve as crystallizing agents, ${ }^{3}$ or in the case of chiral anions like $\left[\mathrm{B}(\mathrm{Binol})_{2}\right]^{-,}{ }^{4}$ or related aryl diborate anions, ${ }^{5}$ as resolving agents via diastereomeric salt formation. ${ }^{6}$ This method of optical resolution has found numerous important applications in the field of organic and pharmaceutical chemistry. ${ }^{7}$ Recently we explored the utility of bis(mandelato)-borate $\left[\mathrm{BMan}_{2}\right]$ anions as resolving agents and found they offered highly efficient resolution of a chemically diverse range of racemic cations. ${ }^{8}$

In this regard it was noted that the anions had permanent $\mathrm{C}$ based chiral centres through use of either $R$-mandelic or $S$ mandelic acid as the starting oxyacid chelate. However the chelation of two asymmetric ligands to tetrahedral $\mathrm{B}$ also creates a stereochemical centre at boron. Chiral borate anions based on such asymmetric bis-chelation was discussed by Lacour in a review of anion design for resolution. ${ }^{9}$ The potential for chirality in such ions was first reported in 1925, with the partial resolution of chiral spiroborate anions derived from 3nitro- and 4-chloro-catechol by brucine or strychnine. ${ }^{10}$ These

Department of Chemistry, Hong Kong University of Science and Technology, Clear Water Bay, Kowloon, Hong Kong, China. E-mail: chwill@ust.hk

$\dagger$ Electronic supplementary information (ESI) available. CCDC 1581657-1581661 and 1581667. For ESI and crystallographic data in CIF or other electronic format see DOI: $10.1039 / \mathrm{c} 7 \mathrm{ra11997f}$ were found to be configurationally labile. Racemization processes for chiral spiroborates were more recently examined by NMR, first by Hosseini $e t$ al. for a chiral boracryptand ${ }^{11}$ and subsequently by Nelson et al. ${ }^{12}$ for two chiral aryl spiroborates. This latter study derived a $\Delta G \$$ of $85 \mathrm{~kJ} \mathrm{~mol}^{-1}$ for the activation energy for racemization for chiral bis(3-isopropylcatecholato) borate $\left[\mathrm{BCat}_{2}{ }_{2}\right]^{-}$in an acidic medium (16 mM benzoic acid), implying rapid scrambling at room temperature ( $\left.t_{1 / 2} \mathrm{ca} .2 \mathrm{~min}\right)$.

In the diastereomeric $\left[\mathrm{BMan}_{2}\right]^{-}$system, DFT calculations indicated that anions with both B-based chiralities are similar in energy, whilst NMR spectra confirmed both co-exist in solution. ${ }^{8}$ However the two anions are markedly different in shape and in the solid state the precipitation of twisted $\left[\mathrm{B}_{S}(R-\mathrm{Man})_{2}\right]$ or $\left[\mathrm{B}_{R}(S-\mathrm{Man})_{2}\right]$ is always observed in crystallized salts, rather than 'V-shaped' $\left[\mathrm{B}_{R}(R \text {-Man })_{2}\right]$ or $\left.\left[\mathrm{B}_{S}(S \text {-Man })_{2}\right]\right]^{8,13}$ Circular dichroism and NMR spectra can be used to track the stability of the $\left[\mathrm{BMan}_{2}\right]$ anions and suggested that in line with previous findings a slow equilibration of bis(mandelato)borate anions occurs in protic solvents such as methanol. However this was not the case in aprotic solvents, such as dimethylformamide (DMF), in which the anions were found to be configurationally stable. ${ }^{8}$

Given this finding we determined to reinvestigate whether Bchiral spiroborates arising from bis-ligation of two asymmetric chelates could first be fully resolved and then similarly shown to exhibit B-based enantiostability in the absence of protic sources. The most obvious choice, with possibility for extending to a wider class, is the use of salicylic acid to form the bis(salicylato)borate anion [ $\left.\mathrm{BSal}_{2}\right]$ (Fig. 1).

Herein we report the successful solid-state isolation of both the $\left[\mathrm{B}_{S}(R-\mathrm{Man})_{2}\right]$ and $\left[\mathrm{B}_{S}(\mathrm{Sal})_{2}\right]$ enantiomers, their X-ray structures, solution circular dichroism (CD) spectra. Furthermore 


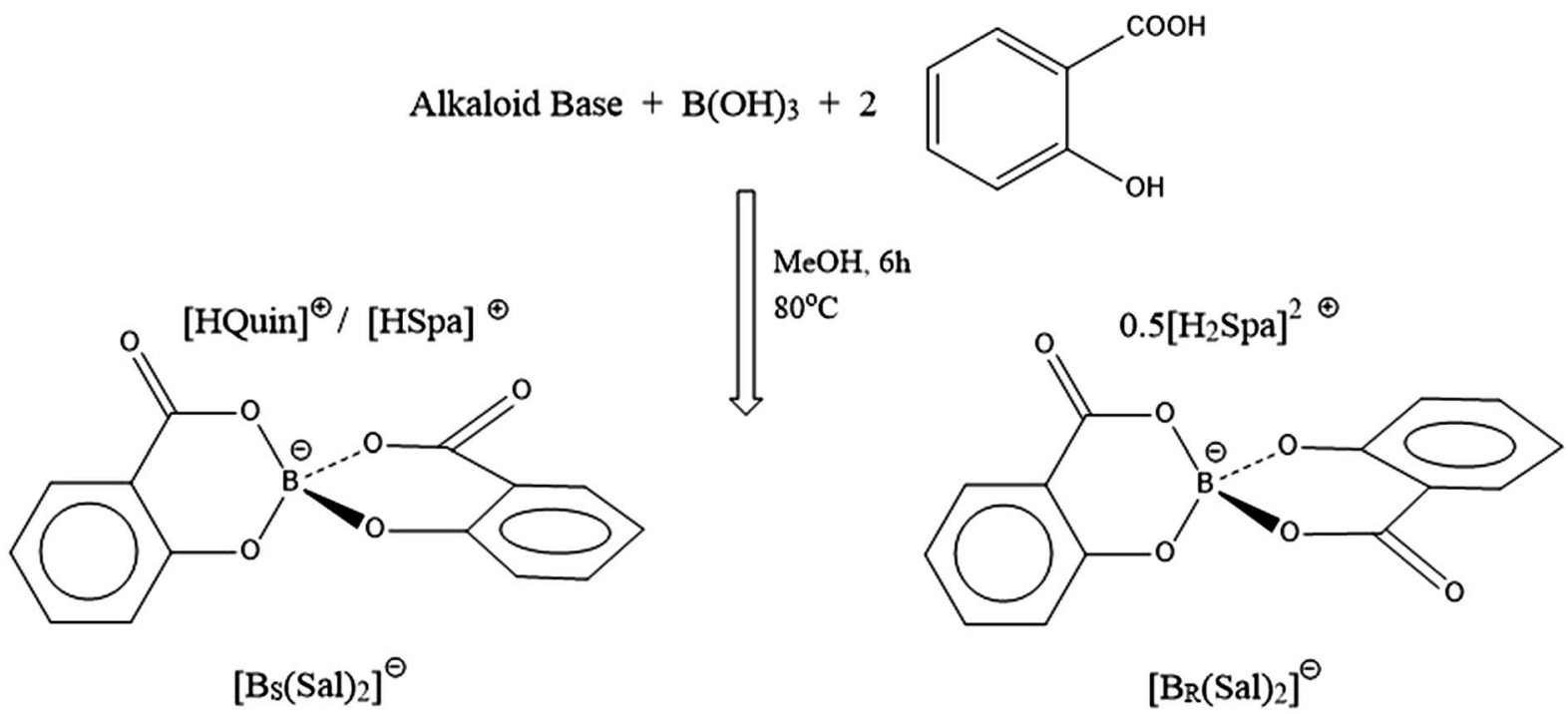

Fig. 1 Preparation of chiral bis(salicylato)borate ions $\left[\mathrm{B}_{R}(\mathrm{Sal})_{2}\right]$ and $\left[\mathrm{B}_{S}(\mathrm{Sal})_{2}\right]$. The subscripted $\mathrm{B}_{R}$ and $\mathrm{B}_{S}$ notations indicate the Cahn-IngoldPrelog stereochemistry at the chiral B centre.

their enantiostability in aprotic solution, as well as their ability to participate in metathesis crystallizations, is demonstrated.

\section{Results/discussion}

\section{Isolation of $\left[\mathrm{B}_{S}(\mathrm{Sal})_{2}\right]$ salts}

Quinine (abbreviated here as Quin) is a chiral alkaloid base isolated from the bark of cinchona sp. with much classical use as a resolving cation and continues to show application for example in the recent reports of resolution of malates and mandelates. ${ }^{14}$ It has two basic sites, a tertiary quinuclidine amine and an aromatic quinoline nitrogen. The former $\mathrm{p} K_{\mathrm{a}}$ is much higher and so typically mono-cations are formed. In the case of bis(salicylato)borate single crystals of a well-resolved salt $[\mathrm{HQuin}]\left[\mathrm{B}_{S}(\mathrm{Sal})_{2}\right] \mathbf{1}$ may be obtained from a simple metathesis crystallization between an aqueous solution of sodium bis(salicylato)borate $\mathrm{Na}\left[\mathrm{BSal}_{2}\right]$ and methanolic quinine free base. Alternatively heating quinine, boric acid and 2 equivalents of salicylic acid in methanol to reflux, or using solvothermal conditions for several hours can result in formation of $\mathbf{1}$ upon cooling (Fig. 1). Single crystal structure determination of 1 readily showed that resolution of the $\left[\mathrm{BSal}_{2}\right]$ ions present in solution was not only possible, but due to dynamic nature of equilibrium between the two anions also in high yield and purity. The experimental details of the crystal structure are given in Table 1 and key geometric features of the $\left[\mathrm{BSal}_{2}\right]$ anions in Table 2.

The X-ray structure of $\mathbf{1}$ (Fig. 2) shows an intermolecular $\mathrm{H}^{-}$ bond between $\mathrm{N} 1-\mathrm{H}$ of the quininium ion to a keto oxygen $\mathrm{O}(10)$ of the $\left[\mathrm{B}_{S}(\mathrm{Sal})_{2}\right]$ anion with $\mathrm{N} \cdots \mathrm{O} 2.800 \AA$. The [HQuin] alcohol forms a $\mathrm{O}(1)-\mathrm{H} \cdots \pi$ hydrogen bond to aromatic ring of the $\left[\mathrm{BSal}_{2}\right]$ anion with the shortest contact $\mathrm{O}(1) \cdots \mathrm{C}(33) 3.214 \AA$. The crystal system is triclinic, space group $P 1$ with one molecular formula per unit cell. The packing may be regarded as reasonably efficient with the $\pi$-systems of the quinoline and one salicylate ligand arm aligning in parallel.
As might be expected the geometry of the $\left[\mathrm{BSal}_{2}\right]$ anion (Table 2) is that of a distorted tetrahedron. The $\mathrm{B}-\mathrm{O}$ bonds are shorter to phenolic oxygen (1.443(2) and 1.446(2) ̊) but longer to the carboxylate oxygens $\mathrm{O}(12)$ and $\mathrm{O}(22)$ (average $1.49 \AA$ ). The external hydrogen bond to keto $\mathrm{O}(10)$ has the effect of modifying the carboxylate resonance forms and the $\mathrm{B}-\mathrm{O}(11)$ 1.502(4) is significantly longer than $\mathrm{B}-\mathrm{O}(21) 1.469(4) \AA$. In general the stronger $\mathrm{B}-\mathrm{O}$ bonds are to ligand $\mathrm{O}$ that are from the stronger conjugate base. This was also seen previously in the bis(mandelato)borate $\left[\mathrm{BMan}_{2}\right]$ anions which have roughly planar 5membered chelate rings. ${ }^{8,13}$ The ring expansion in $\left[\mathrm{BSal}_{2}\right]$ to sixmembered chelates also comes with a greater propensity for ring non-planarity. This is manifested in a considerable deviation of the boron atom from the ring plane of around $0.4 \AA$.

The non-planarity can also be characterized by the dihedral angle $\phi$ formed by the $\mathrm{BO}_{2}$ plane with the planar salicylate. The salicylate can be bent towards the carboxylate ( $\phi$ defined as +ve) or the phenolate $\mathrm{O}$ ( $\phi$ defined as $-\mathrm{ve})$ of the distal ligand with $\phi$ angles typically between \pm 20 to $30^{\circ}$. Density functional calculations (DFT) at the B3-LYP/6-31G* level indicate that such solid-state distortions are energetically preferable to planar 6membered rings. However the potential surface is shallow $<0.5 \mathrm{kcal} \mathrm{mol}^{-1}$, until it starts to rise sharply above dihedral hinge angles $\phi$ in excess of $\pm 35^{\circ}$ (Fig. 3). The consequence of this is that $\left[\mathrm{B}(\mathrm{Sal})_{2}\right]$ anions are conformationally semi-rigid with a considerable degree of shape flexibility which may assist efficient packing and crystallizations.

Once isolated, our main interest in the $\left[\mathrm{B}_{S}(\mathrm{Sal})_{2}\right]$ anions was to see whether the boron based chirality could be stable in solution. A solution of $[\mathrm{HQuin}]\left[\mathrm{B}_{S}(\mathrm{Sal})_{2}\right] \mathbf{1}$ was prepared and circular dichroism spectroscopy was carried out. Strong features due to the chiral spiroborate anion were observed, however the CD spectrum of quininium hydrochloride indicated the region above $300 \mathrm{~nm}$ was partly overlapped by features arising from the cation as well. Nevertheless, studies of the stability of the CD spectral signals indicated that the $\left[\mathrm{BS}(\mathrm{Sal})_{2}\right]$ anion was 
Table 1 X-ray structure determination summaries for $1-5$

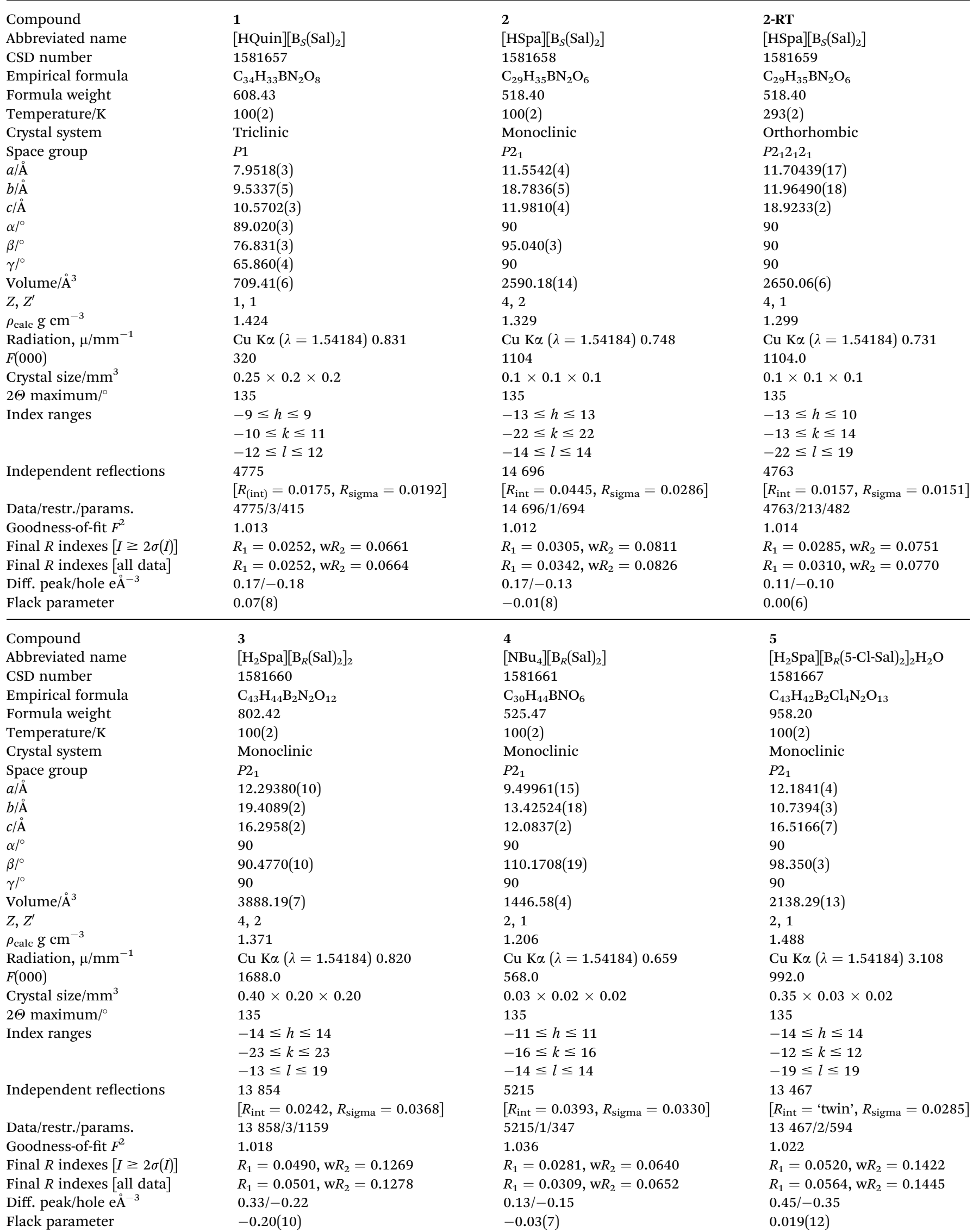


Table 2 Geometry of [BSal* $\left.{ }_{2}\right]$ ions in $1-5^{a}$

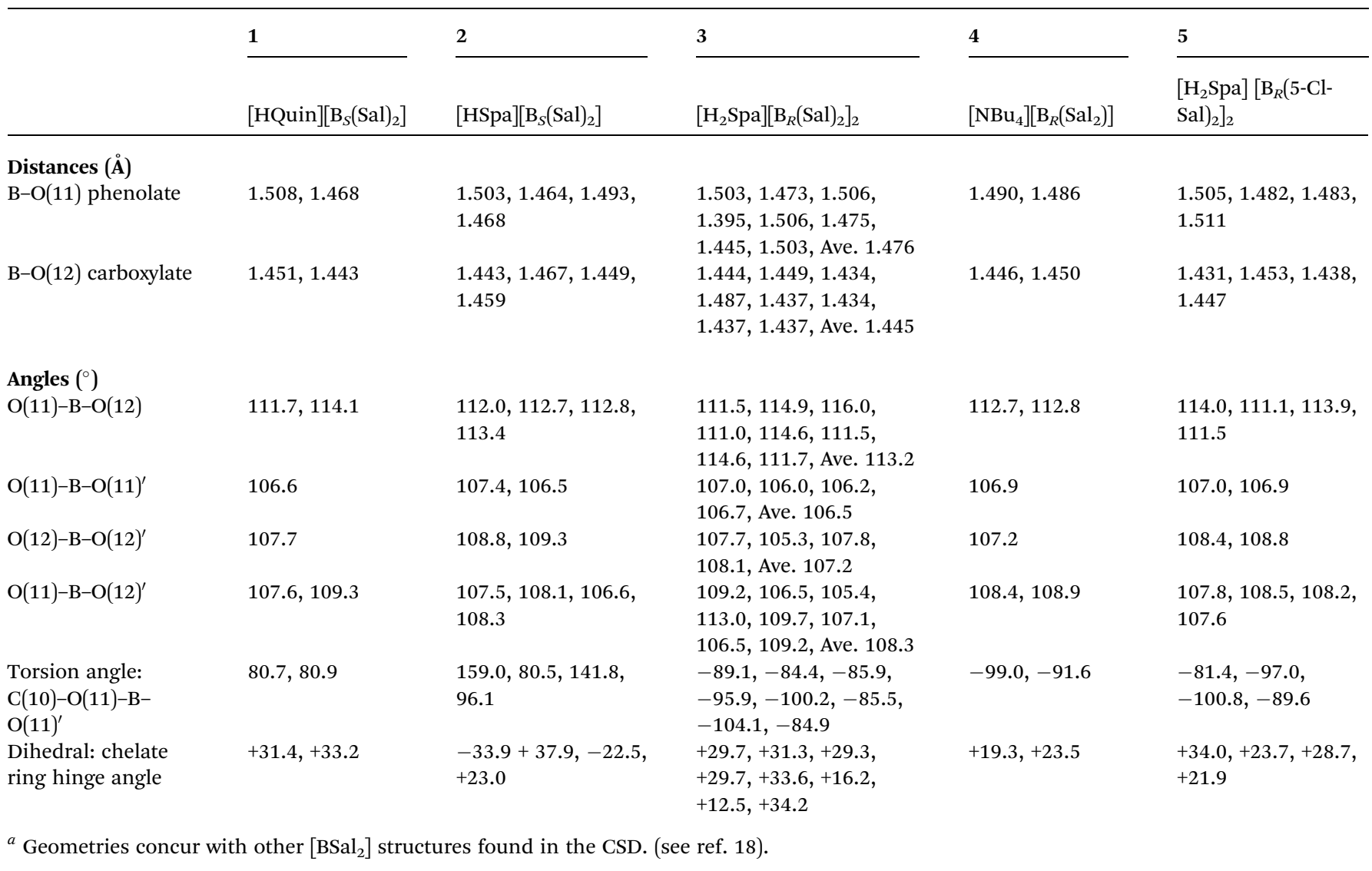

enantiomerically stable in aprotic polar solvents, such as dimethylformamide (DMF). This encouraged its further isolation with a counter-ion which would be CD-silent in the region of interest.

Screening for suitable salt formation with a number of chiral cations, including others derived from alkaloid bases, was carried out. In the case of (-)-sparteine, a dibasic alkaloid frequently used as a chiral auxiliary in organo-lithiation ${ }^{14}$ and coordination catalysis, ${ }^{15}$ an analogous salt 2 , $[\mathrm{HSpa}]\left[\mathrm{B}_{S}(\mathrm{Sal})_{2}\right]$ was prepared in good yield after a short reaction. A single crystal structure of 2 confirmed this was a $1: 1$ salt involving the monoprotonated form of the base (Fig. 4). The crystal structure was found to be monoclinic with space group $P 2_{1}$ (Table 1). However, a check of the powder X-ray diffraction (pXRD) pattern of the bulk material indicated no clear correspondence of peak positions to those simulated from the single crystal structure, although unit cells of further specimens from the sample were in agreement with the original specimen. Further inspection of the structure for 2 showed there were two molecular ion pairs per asymmetric unit $\left(Z^{\prime}=2\right)$ which appeared to be related by pseudo-symmetry. Accordingly the single crystal was reinspected at room temperature (RT) and found to undergo a phase transition to a higher symmetry orthorhombic form with $Z^{\prime}=1$ and space group $P 2_{1} 2_{1} 2_{1}$. Details of 2-RT are given for comparison in Table 1 . The cell undergoes a remarkable change of $\beta$-angle from 95.1 to $90.0^{\circ}$. There is a slightly larger cell volume but anisotropy in the thermal expansion, so that diffraction peaks move to both lower and higher Bragg angles. The simulated pXRD pattern from the RT form 2-RT was then found in excellent agreement with the experimental pattern from the bulk solid indicating phase purity.

The stereochemistry of both crystallographically independent bis(salicylato)borate anions in $\mathbf{2}$ are the same as $\mathbf{1}$. Once again the $\mathrm{B}_{S}$ stereochemistry is exclusively found. As is the case for 1 residual electron density peaks and holes from the structural refinement are below $0.2 \mathrm{e}^{-3}$, consistent with no appreciable disorder of the $\left[\mathrm{Bs}(\mathrm{Sal})_{2}\right]$ anions. The two $[\mathrm{HSpa}]^{+}$cations in 2 have essentially identical geometry in the low temperature structure and an intramolecular $\mathrm{N}(16) \mathrm{H} \cdots \mathrm{N}(1)$ hydrogen bond, which is positionally ordered.

The nitrogen atoms $\mathrm{N}(1)$ at the ring $\mathrm{A} / \mathrm{B}$ junction and $\mathrm{N}(16)$ at the $\mathrm{C} / \mathrm{D}$ ring junction have axial and equatorial lone pairs protonation of the equatorial position is favoured, so [HSpa ${ }^{+}$ has $\mathrm{N}(16)$ as the protonated site (Fig. 3). The $\mathrm{N}(16) \mathrm{H}$ proton also forms a weak $\mathrm{H}$-bond bifurcation to $\mathrm{O}(20)$ of a neighbouring $\left[\mathrm{B}_{S}(\mathrm{Sal})_{2}\right]$ anion with $\mathrm{N} \cdots \mathrm{O}$ separation of $3.09 \AA$ an ion pair from 2 is shown in Fig. 4.

Unlike the case for the quininium salt 1, in 2 the CD spectrum between $270-350 \mathrm{~nm}$ is mostly unaffected by contributions from the monoprotonated sparteinium cation $[\mathrm{HSpa}]^{+}$which is an aliphatic compound with no unsaturated bonds. The CD spectrum for 2 is shown in Fig. 5. The $\left[\mathrm{B}_{S}(\mathrm{Sal})_{2}\right]$ anion shows 


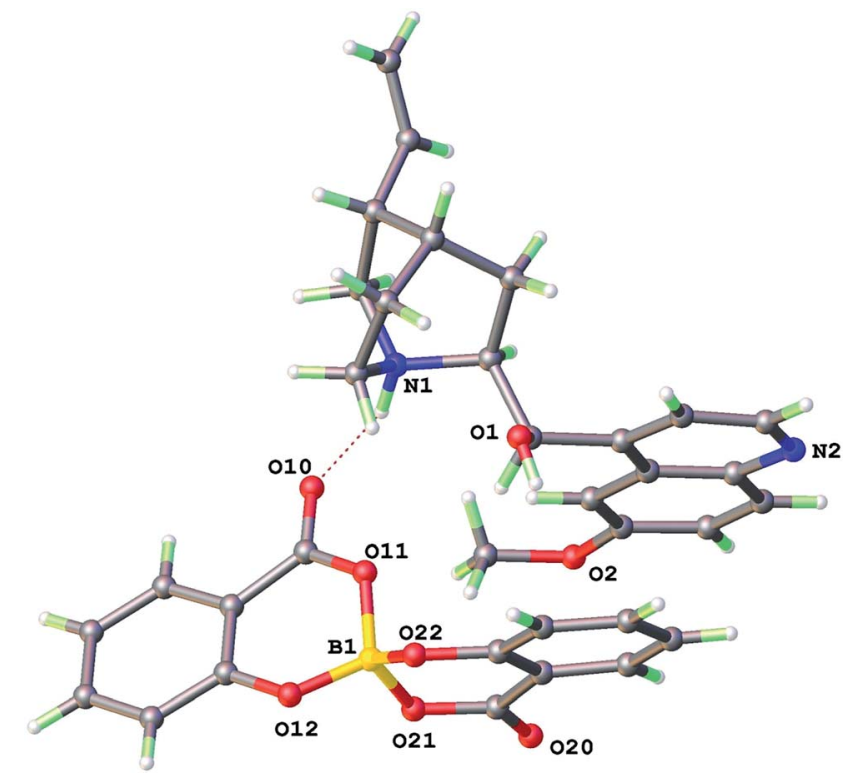

Fig. 2 X-ray structure of ion pair in $1[\mathrm{HQuin}]\left[\mathrm{B}_{S}(\mathrm{Sal})_{2}\right]$.

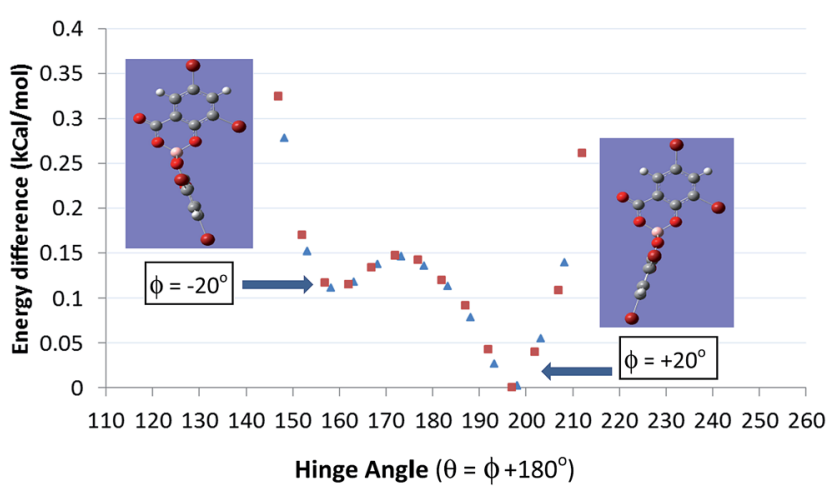

Fig. 3 Energy profile $\left(\mathrm{kcal} \mathrm{mol}^{-1}\right)$ for chelate ring hinge angle in [BSal* ${ }_{2}$ ] ions.

a pronounced negative Cotton effect. The molar ellipticity at the negative trough at $316 \mathrm{~nm}$ is $-\theta=-226 \mathrm{deg} \mathrm{M}^{-1} \mathrm{~cm}^{-1}$. The CD spectrum has a cross-over at the absorption $\lambda_{\max }$ of $304 \mathrm{~nm}$ and a slightly weaker positive peak at $293 \mathrm{~nm}$ with $+\theta=+176$ $\operatorname{deg} \mathrm{M}^{-1} \mathrm{~cm}^{-1}$. The CD spectra of 2 were measured under various conditions to establish $\left[\mathrm{B}_{S}(\mathrm{Sal})_{2}\right]$ enantiostability in aprotic media. In fact DMF solutions of both 1 and 2 give unchanged CD signals over prolonged periods ( $>1$ week). Further tests to explore the addition of water show that moderate amounts (e.g. $4 \mathrm{DMF}: 1 \mathrm{H}_{2} \mathrm{O}$ ) can be tolerated indefinitely, but in pure water the CD signal of 2 is effectively lost over $4 \mathrm{~h}$.

\section{Isolation of $\left[\mathrm{B}_{R}(\mathrm{Sal})_{2}\right]$ salts}

The successful isolation of chiral $\left[\mathrm{B}_{S}(\mathrm{Sal})_{2}\right]$ salts and the finding that these could be enantiostable in aprotic media led us to also seek salts of the mirror image $\left[\mathrm{B}_{R}(\mathrm{Sal})_{2}\right]$ anions. Quinine is unavailable as its mirror image form - quinidine being a diastereomer rather than an enantiomer, whilst (+)-sparteine,

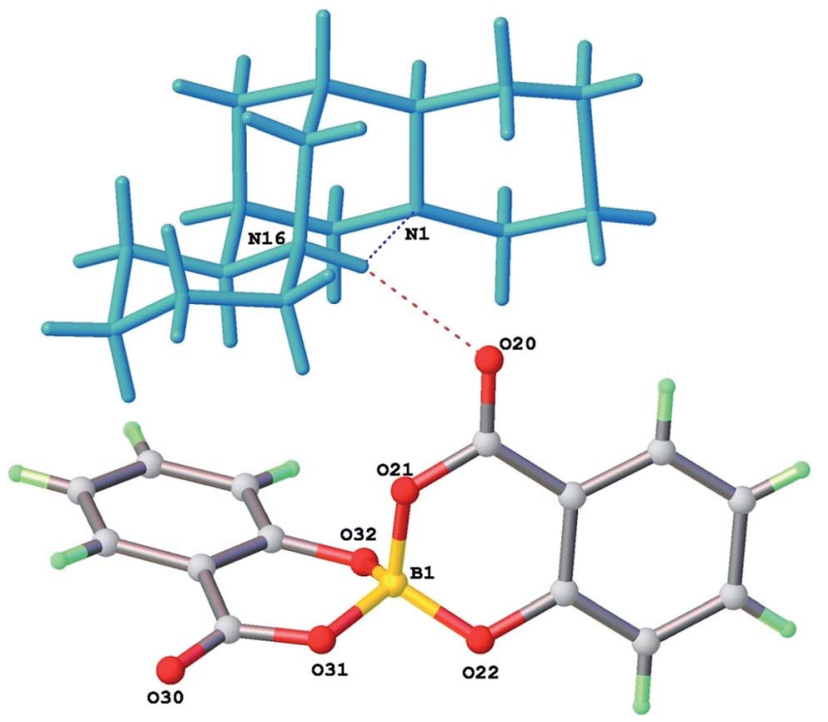

Fig. 4 Ion pair from $2[\mathrm{HSpa}]\left[\mathrm{B}_{S}(\mathrm{Sal})_{2}\right]$ showing bifurcated $\mathrm{H}$-bond from $\mathrm{H}(16)$.

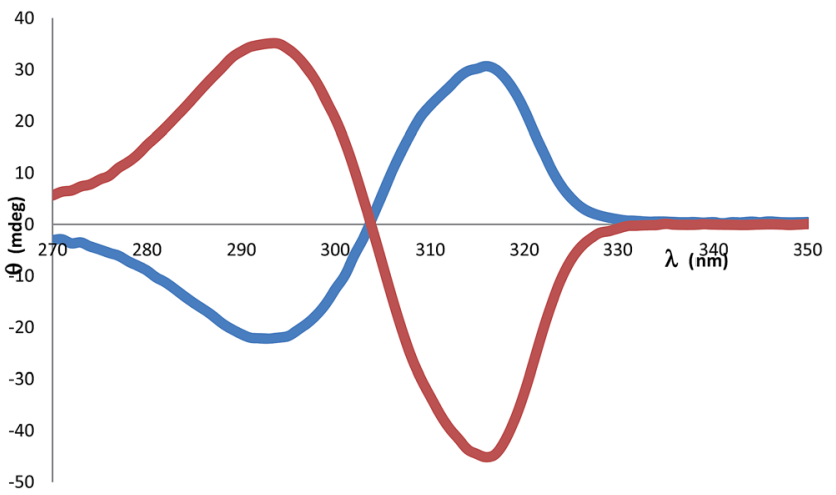

Fig. 5 Circular dichroism spectra for $2[\mathrm{HSpa}]\left[\mathrm{B}_{S}(\mathrm{Sal})_{2}\right] 0.2 \mathrm{mM}$ (red) and $3\left[\mathrm{H}_{2} \mathrm{Spa}\right]\left[\mathrm{B}_{R}(\mathrm{Sal})_{2}\right]_{2} 0.1 \mathrm{mM}$ (blue) in dimethylformamide, indicating $70 \%$ ee for 3 .

a natural product also known as pachycarpine, is commercially available, but expensive.

Fortunately our studies with (-)-sparteine indicated that if longer crystallization times were used, a different phase 3 was then produced rather than 2 . This phase was also favoured if (-)-sparteine sulphate rather than sparteine free base was employed. Since (-)-sparteine is dibasic and known with both mono and diprotonated forms, ${ }^{16}$ it was reasoned that phase 3 might contain the dication. A single crystal specimen was selected and the structure analysis (Table 1) indicated that 3 was indeed a $1: 2$ salt and best formulated as $\left[\mathrm{H}_{2} \mathrm{Spa}\right]\left[\mathrm{B}_{R}(\mathrm{Sal})_{2}\right]_{2}$. The diprotonated form of sparteinium has a major shape change $\mathrm{e}^{\mathbf{1 7}}$ (Fig. 6) and in the 1:2 salt preferentially selects for $\mathrm{B}_{R}$ configurations at the two crystallographically independent $\left[\mathrm{BSal}_{2}\right]$ sites. However structure refinement was not perfectly smooth and residual peaks of about $0.5 \mathrm{e \AA}^{-3}$ could be found at the anion sites consistent with a minor disorder $\left[\mathrm{B}_{S}(\mathrm{Sal})_{2}\right]$, such that the enantio-excess was estimated to be about $80 \%$ ee. This was 

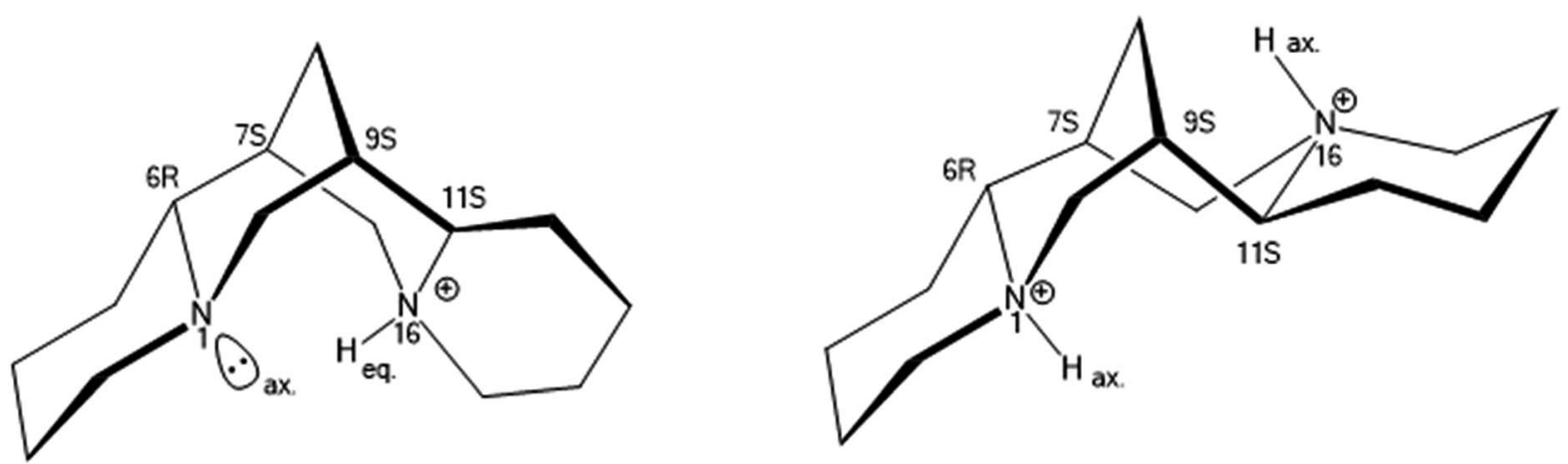

Fig. 6 Spatial relationship of mono and diprotonated sparteinium cations, $[\mathrm{HSpa}]^{+}$and $\left[\mathrm{H}_{2} \mathrm{Spa}\right]^{2+}$ showing shape change.

subsequently borne out by the resulting CD spectrum of 3 , which gave an inverted CD spectrum to 2, but with signals of approximately $70 \%$ ee for the bulk material (Fig. 5). The packing diagram for 3 looking along the a-axis is shown in Fig. 7 and can help explain why $\mathrm{B}_{R} / \mathrm{B}_{S}$ disorder may occur in this salt. As was the case for 2 , the asymmetric unit of 3 has $Z^{\prime}=2$ at low temperature, this means there are two independent $\left[\mathrm{H}_{2} \mathrm{Spa}\right]$ and four $\left[\mathrm{BSal}_{2}\right]$ ions. The two cations are coloured dark and pale green and the four anions labelled as B1-B4. Each of these make self-stacks along the a-axis direction. In order to prepare a salt with enantiopure $\left[\mathrm{B}_{R}(\mathrm{Sal})_{2}\right]$ anions we decided to carry out a metathesis crystallization from the impure salt 3. By exchanging the cation it was hoped the diastereomeric structural disorder found in 3 could be removed.

A dry methanolic solution of $\mathbf{3}$ was prepared and excess $1 \mathrm{M}$ methanolic tetra- $n$-butylammonium hydroxide was added with stirring. A crystalline precipitate formed within $15 \mathrm{~min}$ and was filtered off and characterized. A subsequent crystal structure analysis (Table 1 ) showed the product was $4\left[\mathrm{NBu}_{4}\right]\left[\mathrm{B}_{R}(\mathrm{Sal})_{2}\right]$ (Fig. 8).

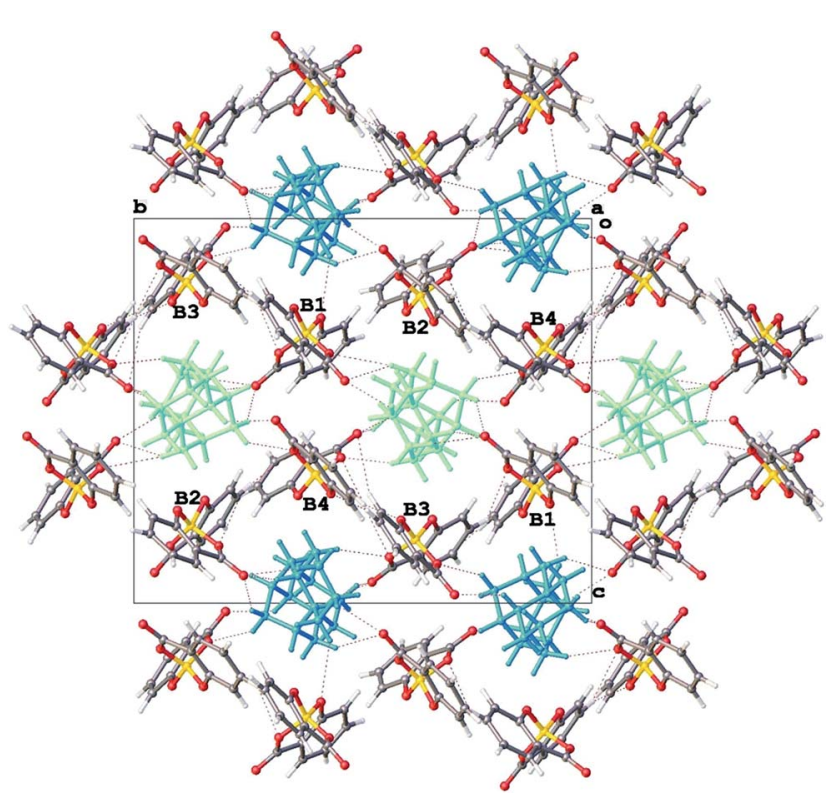

Fig. 7 Packing diagram for $3,\left[\mathrm{H}_{2} \mathrm{Spa}\right]\left[\mathrm{B}(\mathrm{Sal})_{2}\right]_{2}$ along [100].
Structural refinement for $\mathbf{4}$ is well-behaved and no ghost peaks indicating anion disorder are found - residual peak/hole are $+0.13 /-0.15 \mathrm{e \AA}^{-3}$. Furthermore the Flack parameter $-0.03(7)$ refines to an acceptable value close to zero with small standard uncertainty implying racemic twinning in this crystal specimen of 4 is negligible. p-XRD pattern of bulk powder indicates the crystalline peaks belong to a mixture of enantiopure 4 and a racemic phase that can be formed from direct reaction of $\left[\mathrm{NBu}_{4}\right] \mathrm{OH}$ with boric and salicylic acids. The CD spectrum of this powder mixture showed the overall enantiopurity of the material was unchanged, based on the molar values established for $\left[\mathrm{B}_{S}(\mathrm{Sal})_{2}\right]$ in 2 .

The importance of this material's isolation was that metathesis crystallization of chiral bis(salicylato)borate anions is possible with retention of configuration. Since the $\left[\mathrm{NBu}_{4}\right]^{+}$ counterion is a simple aliphatic one and unlike quininium or sparteinium ions has no protic site, this is a more enantio-robust salt, so may be more suitable for use in further resolutions. One final point worth mentioning for $\mathbf{4}$ is that its' bis(mandelato) borate analogue $\left[\mathrm{NBu}_{4}\right]\left[\mathrm{B}_{R}(S \text {-Man })_{2}\right]$ is a low melting solid and differential scanning calorimetry (DSC) indicates it melts just below $30{ }^{\circ} \mathrm{C}^{13}$ In the case of $\left[\mathrm{NBu}_{4}\right]\left[\mathrm{BSal}_{2}\right] \mathbf{4}$ we have found a higher melting point at $115{ }^{\circ} \mathrm{C}$, underscoring the idea that the bis(salicylato)borate ion is more rigid. Further engineering of ionic liquids by varying counter cation and salicylate substituents could be of some interest, given the demonstration of enantiostability of the $\left[\mathrm{BSal}_{2}\right]$ anions in aprotic media.

In principle therefore either hand of $\left[\mathrm{BSal}_{2}\right]$ could be prepared from suitable reaction with sparteine base, albeit a simpler one-step procedure for $\left[\mathrm{B}_{R}(\mathrm{Sal})_{2}\right]$ is still being sought. Indeed the disorder present in the structure of $3\left[\mathrm{H}_{2} \mathrm{Spa}\right]$ $\left[\mathrm{B}_{R}(\mathrm{Sal})_{2}\right]_{2}$ was rather surprising, but can be seen as a consequence of similar non-bonded contacts being formed for the two salicylate orientations. In principle appropriate ring substitution should break the approximate degeneracy of packing and yield cleaner disorder-free salts.

To prove this and show that chiral spiroborates derived from salicylic acids can be readily extended we carried out reaction of sparteine, boric and 5-chlorosalicylic acid and make an analogous salt to 3 . The product was formed in excellent yield and purity and a crystal structure revealed 5 to be the monohydrate of the $1: 2$ salt $\left[\mathrm{H}_{2} \mathrm{Spa}\right]\left[\mathrm{B}_{R}(5-\mathrm{Cl}-\mathrm{Sal})_{2}\right]_{2} \cdot \mathrm{H}_{2} \mathrm{O}$. The two 


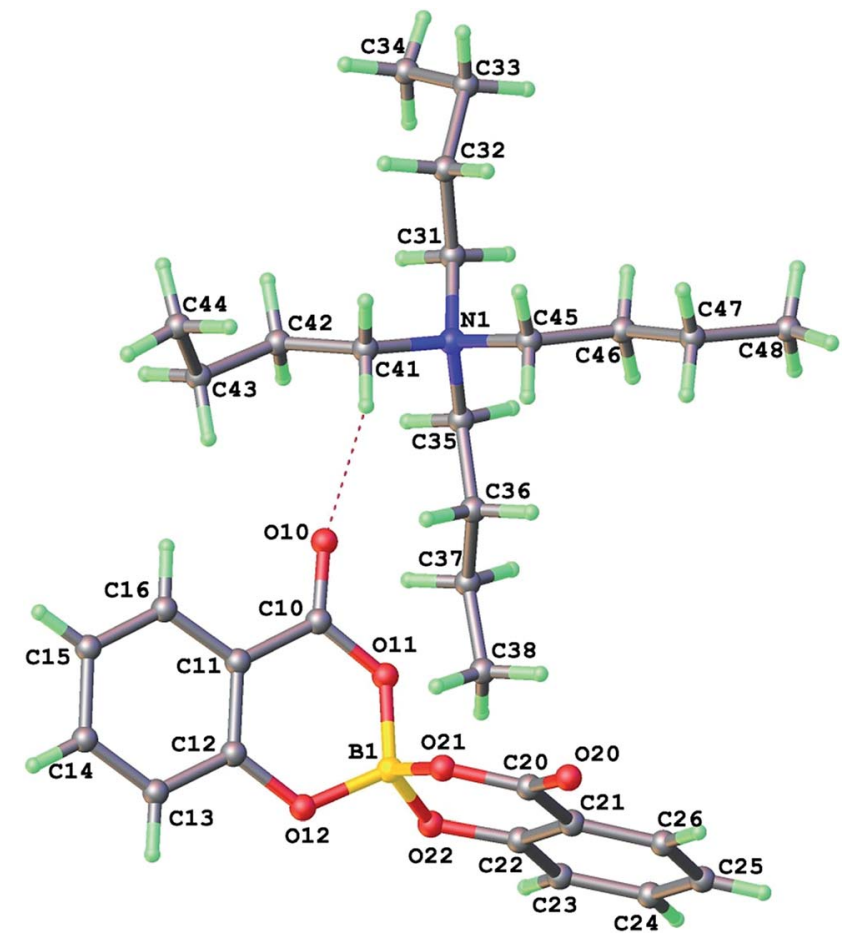

Fig. 8 Crystal structure of the salt $\left[\mathrm{NBu}_{4}\right]\left[\mathrm{B}_{R}(\mathrm{Sal})_{2}\right] 4$, showing the ion pair of the asymmetric unit.

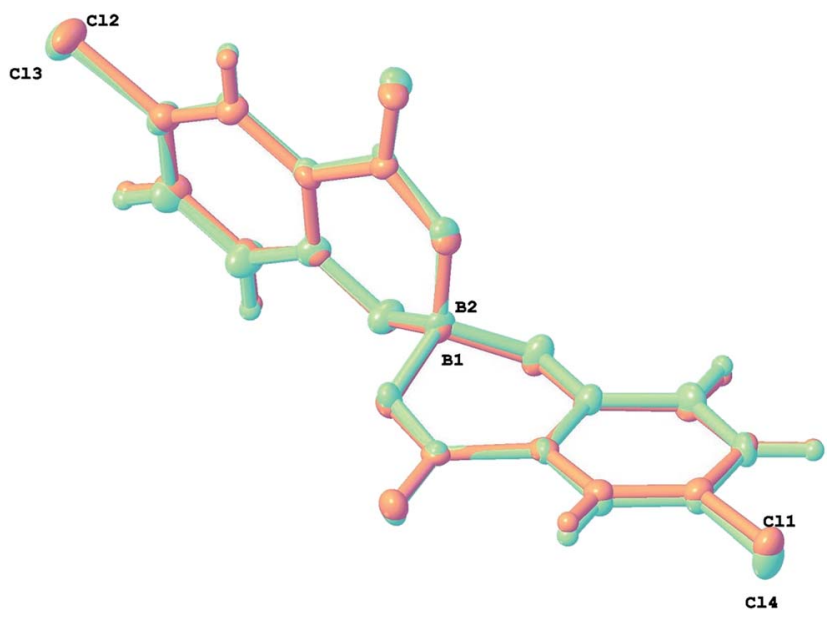

Fig. 9 Overlay of the two independent $\left[\mathrm{B}_{R}(5-\mathrm{Cl}-\mathrm{Sal})_{2}\right]$ anions in 5 - all chelate rings are 'hinged' towards the carboxy $\bigcirc$ of the other chelating ligand.

independent anion sites in the crystal are both consistent with enantiopure $\left[\mathrm{B}_{R}(5-\mathrm{Cl}-\mathrm{Sal})_{2}\right]$ configurations. They are shown together as an overlay in Fig. 9 which emphasizes their very similar geometry. The dihedral 'hinge' angles of the chelate rings are +34.0 and +23.9 for $\mathrm{B}(1)$ anion and +28.8 and $+22.2^{\circ}$ for the $\mathrm{B}(2)$ anion (Table 2 ), positive values implying the hinge is bent towards the distal carboxy $\mathrm{O}$ rather than phenoxy $\mathrm{O}$.

The electronic perturbation of the salicylate anion by introduction of the 5-chloro substituent has a subtle effect on the CD spectrum, which was measured after dehydration of the solid. There is a distinct red shift of all the CD spectral features, which
Table 3 Circular dichroism spectral features for [BSal* ${ }_{2}$ ] anions ${ }^{a}$

\begin{tabular}{lll}
\hline Anion & {$\left[\mathrm{B}_{S}(\mathrm{Sal})_{2}\right]$} & {$\left[\mathrm{B}_{R}(5-\mathrm{Cl}-\mathrm{Sal})_{2}\right]$} \\
\hline $\begin{array}{l}\text { UV-vis absorption } \\
\lambda_{\max }(\mathrm{nm})\end{array}$ & & \\
$\varepsilon_{\max }\left(\mathrm{M}^{-1} \mathrm{~cm}^{-1}\right)$ & 904 & 317 \\
Circular dichroism & 9725 & 8210 \\
$\lambda(+\theta)(\mathrm{nm})$ & \\
$+\theta\left(\mathrm{deg} \mathrm{M}^{-1} \mathrm{~cm}^{-1}\right)$ & 293 & \\
$+\Delta \varepsilon\left(\mathrm{M}^{-1} \mathrm{~cm}^{-1}\right)$ & +176 & 330 \\
$\lambda(-\theta)\left(\mathrm{nm}^{-1} \mathrm{~cm}^{-1}\right)$ & +53.2 & +252 \\
$-\theta\left(\mathrm{deg} \mathrm{M} \mathbf{M}^{-1}\right.$ & 316 & +76.4 \\
$-\Delta \varepsilon\left(\mathrm{M}^{-1} \mathrm{~cm}^{-1}\right)$ & -226 & 305 \\
Cotton effect & -68.5 & -164 \\
\end{tabular}

${ }^{a}$ (See ESI data for CD spectra showing racemization or enantiostability of $\left[\mathrm{B}_{R}(\mathrm{Sal})_{2}\right]$ ions in different media and CD spectrum of $\left.\left[\mathrm{B}_{R}(5-\mathrm{Cl}-\mathrm{Sal})_{2}\right]\right)$.

can be attributed to the corresponding shift in the UV-vis absorption spectrum $\left(\lambda_{\max }=317 \mathrm{~nm}\right)$. Assuming the isolated salt 5 is enantiopure, the molar ellipticity values at the Cotton effect peak $+\theta_{(330 \mathrm{~nm})}=+252 \mathrm{deg} \mathbf{M}^{-1} \mathrm{~cm}^{-1}$ and trough $-\theta_{(305 \mathrm{~nm})}$ $=-164 \mathrm{deg} \mathrm{M}^{-1} \mathrm{~cm}^{-1}$ for $\left[\mathrm{B}_{R}(5-\mathrm{Cl}-\mathrm{Sal})_{2}\right]$. (CD spectrum shown in Fig. S10, ESI data $\dagger$ ). Table 3 lists these for comparison with the CD parameters for the $\left[\mathrm{B}_{S}(\mathrm{Sal})_{2}\right]$ anion, which was discussed earlier. The inverted $\mathrm{B}_{R}$ chirality in the case of 5 leads to a positive Cotton effect.

Successful isolation of $\mathbf{5}$ and the enantiopurity and enantiostability of such spiroborate compounds implies that a much wider family of bis(salicylato)borate anions $\left[\mathrm{B}\left(\mathrm{Sal}^{*}\right)_{2}\right]$ with substituted salicylates may be prepared and isolated as either their $\mathrm{B}_{R}$ or $\mathrm{B}_{S}$ salts using appropriate resolving cations. These may then have their own prospective use in either metathesis based resolutions, or even in chiral ionic liquid formulations. ${ }^{19}$

\section{Experimental}

\section{Materials and methods}

All chemicals were reagent grade $(99 \%+)$ from reputable commercial sources (Sigma-Aldrich or Acros). Quinine was used as its free base, sparteine either as free base or as diprotonated sulphate salt pentahydrate. Tetrabutylammonium hydroxide (TBAH) was a $1 \mathrm{M}$ methanolic solution. Elemental combustion analyses were carried out by Medac Ltd., Surrey, U.K.

\section{Synthetic procedures}

Salts 2, 3 and 5 were prepared by a facile one-pot procedure involving direct reaction of the resolving alkaloid base with boric and salicylic acids in appropriate molar ratio. Salt $\mathbf{1}$ is more reliably prepared by a prior isolation of anhydrous $\mathrm{Na}$ $\left[\mathrm{BSal}_{2}\right]$ from boric flux ${ }^{20}$ reaction of $\mathrm{NaOH}$, boric acid and salicylic acid in $1: 1: 2$ ratio at $110{ }^{\circ} \mathrm{C}$ for 1 day. Salt 4 is prepared from a cation metathesis exchange from 3 .

1 [HQuin] $\left[\mathbf{B}_{S}(\mathbf{S a l})_{2}\right]$. Sodium bis(salicylato)borate $\mathrm{Na}\left[\mathrm{BSal}_{2}\right]$ (see below) (1 mmol, Fw 306.14, $306 \mathrm{mg}$ ) in $10 \mathrm{~mL}$ of water was layered with quinine ( $1 \mathrm{mmol}$, Fw 324.42, $0.325 \mathrm{~g}$ ) in $10 \mathrm{~mL}$ methanol in a crystallization tube for 1 week. The resulting pale 
yellow crystals were filtered and washed by minimal amount of ethanol $(0.424 \mathrm{~g}, 70 \%)$. Combustion analysis: calculated for $\mathrm{C}_{34} \mathrm{H}_{33} \mathrm{BN}_{2} \mathrm{O}_{8}$ (found) \% $\mathrm{C}=67.12$ (67.25); \% $\mathrm{H}=5.47$ (5.20); $\% \mathrm{~N}=4.60$ (4.43).

2 [HSpa][ $\left.\mathbf{B}_{S}(\mathrm{Sal})_{2}\right]$. Salicylic acid ( $\left.2 \mathrm{mmol}, \mathrm{Fw} 138.12,0.276 \mathrm{~g}\right)$, boric acid (1 mmol, Fw 61.8, $0.062 \mathrm{~g}$ ), sparteine (1 mmol, Fw $234.38,0.234 \mathrm{~mL}$ ), in $1 \mathrm{~mL}$ methanol were mixed in a $23 \mathrm{~mL}$ Teflon cup, sealed in steel autoclave and heated at $80{ }^{\circ} \mathrm{C}$ for 4 hours. The resulting colourless blocks were filtered and washed with minimal amount of ethanol $(0.403 \mathrm{~g}$, Fw 518.41, 78\% yield). Combustion analysis: calculated for $\mathrm{C}_{29} \mathrm{H}_{35} \mathrm{BN}_{2} \mathrm{O}_{6}$ (found) $\% \mathrm{C}=$ 67.19 (67.17); \% $\mathrm{H}=6.80$ (6.73); \% $\mathrm{N}=5.40$ (5.47).

$3\left[\mathbf{H}_{2} \mathrm{Spa}\right]\left[\mathbf{B}_{R}(\mathrm{Sal})_{2}\right]_{2}$. (-)-Sparteine sulphate $(1 \mathrm{mmol}$, $442 \mathrm{mg}$ ), sodium bis(salicylato)borate $\mathrm{Na}\left[\mathrm{BSal}_{2}\right]$ (2 mmol, $665 \mathrm{mg}$ ), $5 \mathrm{~mL}$ methanol/ $\mathrm{H}_{2} \mathrm{O}$ (4:1) were mixed in a Teflon cup, and heated at $80{ }^{\circ} \mathrm{C}$ for 12 hours. The resulting white sample was dried and the crystal was filtered and washed with small amount of ethanol to give white block with $76 \%$ yield. Combustion analysis: calculated for $\mathrm{C}_{43} \mathrm{H}_{44} \mathrm{~B}_{2} \mathrm{~N}_{2} \mathrm{O}_{12}$ (found) $\%$ $\mathrm{C}=64.36$ (62.35); \% $\mathrm{H}=5.53$ (4.58); \% $\mathrm{N}=3.49$ (3.02).

$4\left[\mathrm{NBu}_{4}\right]\left[\mathrm{B}_{R}(\mathrm{Sal})_{2}\right] .3$ (Fw 802.4, $1 \mathrm{mmol}, 800 \mathrm{mg}$ ) was stirred with tetra- $n$-butylammonium hydroxide (TBAH) ( $2 \mathrm{mmol}$, $1.5 \mathrm{~mL}$ ) in $10 \mathrm{~mL}$ methanol in room temperature under $\mathrm{N}_{2}$ for $30 \mathrm{~min}$. The resulting white crystalline solid was filtered, washed with small amount of ethanol and dried to give white blocks of 4 (470 mg, Fw 525.5, 45\% yield). Combustion analysis: calculated for $\mathrm{C}_{30} \mathrm{H}_{44} \mathrm{BNO}_{6}$ (found) $\% \mathrm{C}=68.57$ (68.98); \% $\mathrm{H}=$ 8.44 (8.74); \% N = 2.67 (2.55). Mp $115{ }^{\circ} \mathrm{C}$ (TA instruments Q1000 differential scanning calorimeter).

\section{$5\left[\mathbf{H}_{2} \mathrm{Spa}\right]\left[\mathrm{B}_{\boldsymbol{R}}(\mathbf{5}-\mathrm{Cl}-\mathrm{Sal})_{2}\right]_{2}$}

Method A. 5-Chlorosalicylic acid $263 \mathrm{mg}$, (2 mmol), $31 \mathrm{mg}(0.5$ mmol) boric acid, $28 \mathrm{mg}(0.5 \mathrm{mmol}) \mathrm{KOH}$, were mixed with (-)-sparteine sulphate $(0.25 \mathrm{mmol}, 106 \mathrm{mg})$ and EtOH mixed in glass vial, sealed and heated at $80{ }^{\circ} \mathrm{C}$ for $4 \mathrm{~h}$. After cooling to ambient temperature, colourless crystals were filtered and washed by minimal amounts of water and acetone to give $74 \%$ yield of 5 as its monohydrate.

Method B. Sodium bis(5-chloro-salicylato)borate (1 mmol, Fw $379.09,0.379 \mathrm{~g})$ in $3 \mathrm{~mL}$ of ethanol were layered with (-)-sparteinium sulphate pentahydrate (1 mmol, Fw 422.54, $0.422 \mathrm{~g}$ ) in $3 \mathrm{~mL}$ water. The mixture was layered in a crystallization tube for 3 days. The resulting colorless crystal was filtered and washed by minimal amount of ethanol $(0.601 \mathrm{~g}$, Fw 958.23, 63\% yield).

\section{Synthesis of racemic $\mathrm{Na}\left[\mathrm{B}(\mathrm{Sal})_{2}\right]$ and $\mathrm{Na}\left[\mathrm{B}(5-\mathrm{Cl}-\mathrm{Sal})_{2}\right]$ salts}

Salicylic acid (20 mmol, Fw 138.12, $2.76 \mathrm{~g}$ )/or 5-chlorosalicylic acid (20 mmol, Fw 172.57, $3.45 \mathrm{~g}$ ), boric acid (10 mmol, Fw $61.8,0.620 \mathrm{~g})$, sodium hydroxide ( $10 \mathrm{mmol}, \mathrm{Fw} 40.0,0.40 \mathrm{~g})$, in $30 \mathrm{~mL}$ ethanol were heated at reflux in a $100 \mathrm{~mL}$ RB-flask for 4 hours. The solutions were concentrated to around $10 \mathrm{~mL}$ and diethyl ether $(20 \mathrm{~mL})$ added until precipitation was complete. The white solid samples were filtered and washed with minimal amount of cold ethanol $(76 \%$ and $72 \%$ yield respectively), which were used for metathesis crystallizations without further purification.

\section{Circular dichroism (CD) spectroscopy}

Combined UV-vis absorption and circular dichroism spectra were run in dimethylformamide (DMF) solution on a Chirascan ${ }^{\mathrm{TM}}$ (Applied Photophysics) spectrophotometer between $270-370 \mathrm{~nm}$ with $0.2 \mathrm{~nm}$ steps. Typical concentration ranges were 0.1-0.01 mmol. Spectral features (Cotton effect) for chiral $\left[\mathrm{B}(\mathrm{Sal})_{2}\right]$ anions were found around $300 \mathrm{~nm}$ in which range marked interference from quininium, but not sparteinium cations was found. Spectral stability was measured at ambient temperature in pure water, pure DMF or mixed $\mathrm{H}_{2} \mathrm{O}$ / DMF solutions for periods up to 1 week (Fig. S3-S9†).

\section{Crystallography}

Single crystal structures for 1-5 (Table 1) were carried out on a Rigaku OD Supernova diffractometer operating with $\mathrm{Cu}-\mathrm{K} \alpha$ radiation at $100 \mathrm{~K}$ unless otherwise noted. Structure solution and refinement were carried out with the Olex2 software package $^{21}$ or SHELXTL ${ }^{22}$ configured to run within that GUI platform. All structures solved and refined in Sohncke (chiral) space groups. Twin laws were applied to structures of $\mathbf{2}$ and $\mathbf{5}$ substantially improving their refinement and final discrepancy indices. In the case of $\mathbf{5}$ this results in difficulty assigning an appropriate $R_{\text {int }}$ for merging data. These were rotational not enantiomorphic twins, since these phases involve sparteinium ions of fixed chirality. Phase 3 showed positional disorder for the two independent anion sites with a minor component of $\left[\mathrm{B}_{S}(\mathrm{Sal})_{2}\right]$ anion juxtaposed at the predominantly $\left[\mathrm{B}_{R}(\mathrm{Sal})_{2}\right]$ sites with approximate occupancy factors of at the $\mathrm{B}(1)$ and at the $\mathrm{B}(2)$ site. All non-hydrogen atoms were refined with anisotropic thermal parameters excepting these minor component atoms which were isotropic and with bond length restraints applied. Protonation states of alkaloid cations were clearly established by identification of sensibly located electron density peaks for $\mathrm{H}$ associated with $\mathrm{N}$ heteroatoms. The Flack parameters of all three structures are zero or slightly negative with s.u.'s below 0.1 , supporting the expected absolute chirality for quininium and (-)-sparteinium ions and establishing the handedness of the $\left[\mathrm{BSal}_{2}\right]$ ions in these structures.

Powder X-ray diffraction measurements for bulk samples of solids 1-5 were made in the range $2 \Theta 5-40^{\circ}$ with step size of $0.02^{\circ}$ on a PANalytical Xpert Pro powder diffractometer fitted with Xcelerator detector strip. These were in good agreement with the patterns simulated from single crystal structure determinations (see ESI data $\dagger$ ) with the exception of compound 2. This resulted from a low temperature structural phase transition which transformed the cell from orthorhombic to monoclinic symmetry with a change of $\beta>5^{\circ}$. An ambient temperature structure determination gave a modified simulated p-XRD pattern which then agreed with that measured experimentally.

\section{Computation}

DFT calculations on idealized $\left[\mathrm{BSal}_{2}\right]$ anions were conducted using Gaussian 09 program ${ }^{23}$ with $6-31 G^{*}$ basis set employing a Becke 3-parameter Lee-Yang-Parr functional (B3LYP). ${ }^{24}$ 
Starting geometries were obtained from crystal structure and energies optimized with constraint applied to salicylate hinge angles, which was varied in $5^{\circ}$ steps. These indicated coplanar rings were disfavoured by $0.25 \mathrm{kcal} \mathrm{mol}^{-1}$ compared to hinged minima.

\section{Conclusions}

Salts of both enantiomeric hands of the B-chiral bis(salicylato) borate $\left[\mathrm{BSal}_{2}\right]$ anions may be been prepared by facile one-pot or metathesis procedures. The $1: 1$ quininium salt [HQuin] $\left[\mathrm{B}_{S}(\mathrm{Sal})_{2}\right]$ and $1: 2$ sparteinium salt $\left[\mathrm{SpaH}_{2}\right]\left[\mathrm{B}_{R}(\mathrm{Sal})_{2}\right]_{2}$ were formed in high yield. Single crystal structure determinations indicate high enantiopurity in the former and about $70 \%$ ee in the latter, due to disorder at one of four independent anion sites. By using 5-chloromandelic acid the analogous salt $\left[\mathrm{H}_{2} \mathrm{Spa}\right]$ $\left[\mathrm{B}_{R}(5-\mathrm{Cl}-\mathrm{Sal})_{2}\right]_{2}$ can be isolated in enantiomerically pure form. Circular dichroism (CD) measurements indicate a strong characteristic spectrum is found for the $\left[\mathrm{BSal}_{2}\right]$ anion. In pure water the resolved $\left[\mathrm{BSal}_{2}\right]$ ions rapidly lose their enantiopurity over time and are fully racemic after about $2 \mathrm{~h}$. However in aprotic DMF solution the CD signals remain completely unchanged after 1 week and even remain unperturbed by addition of up to $25 \%$ water. The B-chiral anions can be also be metathesized into salts such as $\left[\mathrm{NBu}_{4}\right]\left[\mathrm{B}_{R}(\mathrm{Sal})_{2}\right]$, implying that they may have prospects for use in both crystallizations and resolutions.

\section{Conflicts of interest}

There are no conflicts to declare.

\section{Acknowledgements}

The authors are grateful for support of this work from the Research Grants Council of Hong Kong (grant 605511). We also thank Ms Carmen Tse for assistance with the DFT calculations.

\section{References}

1 C. M. Vogels and S. A. Westcott, Chem. Soc. Rev., 2011, 40, 1446-1458.

2 D. M. Schubert, Struct. Bonding, 2003, 105, 1-40.

3 W. Clegg, A. J. Scott, F. J. Lawlor, N. C. Norman, T. B. Marder, C. Y. Dai and P. Nguyen, Acta Crystallogr., Sect. C: Cryst. Struct. Commun., 1998, 54, 1875-1880; W. Clegg, M. R. J. Elsegood, A. J. Scott, T. B. Marder, C. Y. Dai, N. C. Norman, N. L. Pickett and E. G. Robins, Acta Crystallogr., Sect. C: Cryst. Struct. Commun., 1999, 55, 733739.

4 M. Periasamy, N. S. Kumar, S. Sivakumar, V. D. Rao, C. R. Ramanathan and L. Venkatraman, J. Org. Chem., 2001, 66, 3828-3833; M. Periasamy, L. Venkatraman, S. Sivakumar, N. Sampathkumar and C. R. Ramanathan, $J$. Org. Chem., 1999, 63, 7643-7645; M. Periasamy, C. R. Ramanathan and N. S. Kumar, Tetrahedron: Asymmetry, 1999, 10, 2307-2310.
5 Y. Loewer, C. Weiss, A. T. Biju, R. Frohlich and F. Glorius, J. Org. Chem., 2011, 76, 2324-2327.

6 E. L. Eliel, S. H. Wilen and L. N. Mander, Stereochemistry of Organic Compounds, Wiley, New York, 1994.

7 R. Siedlecka, Tetrahedron, 2013, 69, 6331-6363; F. Faigl, E. Fogassy, M. Nogradi, E. Palovics and J. Schindler, Tetrahedron: Asymmetry, 2008, 19, 519-536.

8 L. W.-Y. Wong, J. W.-H. Kan, T. Nguyen, H. H.-Y. Sung, D. Li, A. S.-F. Au Yeung, R. Sharma, Z. Lin and I. D. Williams, Chem. Commun., 2015, 51, 15760-15763.

9 J. Lacour and V. Hebbe-Viton, Chem. Soc. Rev., 2003, 32, 373382.

10 J. Böeseken and J. A. Mijis, Recl. Trav. Chim. Pays-Bas, 1925, 44, 758.

11 E. Graf, R. Graff, M. W. Hosseini, C. Huguenard and F. Taulelle, Chem. Commun., 1997, 1459-1460.

12 S. Green, A. Nelson, S. Warriner and B. Whittaker, J. Chem. Soc., Perkin Trans. 1, 2000, 4403-4408.

13 L. W.-Y. Wong, J. W.-H. Kan, H. H.-Y. Sung and I. D. Williams, Acta Crystallogr., Sect. C: Struct. Chem., 2017, 73, 625-631.

14 N. B. Bathori, A. Jacobs, L. R. Nassimbeni and B. K. Sebogisi, S. Afr. J. Chem., 2014, 67, 160-166; N. B. Bathori, L. R. Nassimbeni and C. L. Oliver, Chem. Commun., 2011, 47, 2670-2672.

15 C. Strohmann, K. Strohfeldt and D. Schildbach, J. Am. Chem. Soc., 2003, 125, 13672-13673.

16 A. G. De Crisci, V. T. Annibale, G. K. Hamer, A. J. Lough and U. Fekl, Dalton Trans., 2010, 39, 2888-2902.

17 B. Wiberg and W. F. Bailey, J. Mol. Struct., 2000, 556, 239.

18 A. Downard, M. Nieuwenhuyzen, K. R. Seddon, J. A. van den Berg, M. A. Schmidt, J. F. S. Vaughan and U. Welz-Biermann, Cryst. Growth Des., 2002, 2, 111-119; H. X. Liu, Q. Liu, H. M. Guo, K. Q. Ye, J. Z. Xiao, X. S. Tai and G. Zeng, Asian J. Chem., 2015, 25, 10601; Y. Yang, S. Pan, X. Hou, J. Guo, F. Li, J. Han, J. Guo and D. Jia, Inorg. Chim. Acta, 2011, 365, 20-24.

19 M. Taher, F. U. Shah, A. Filippov, P. de Baets, S. Glavatskih and O. N. Antzukin, RSC Adv., 2014, 4, 30617-30623.

20 M. M. Wu, T. S.-C. Law, H. H.-Y. Sung, J. W. Cai and I. D. Williams, Chem. Commun., 2005, 1827-1829; H. H.-Y. Sung, M. M. Wu and I. D. Williams, Inorg. Chem. Commun., 2000, 3, 401-404; I. D. Williams, M. M. Wu, H. H.-Y. Sung, X. X. Zhang and J. H. Yu, Chem. Commun., 1998, 2463-2464.

21 O. V. Dolomanov, L. J. Bourhis, R. J. Gildea, J. A. K. Howard and H. Puschmann, J. Appl. Crystallogr., 2009, 42, 339-341; L. J. Bourhis, O. V. Dolomanov, R. J. Gildea, J. A. K. Howard and H. Puschmann, Acta Crystallogr., Sect. A: Found. Adv., 2015, 71, 59-75.

22 G. M. Sheldrick, Acta Crystallogr., Sect. C: Struct. Chem., 2015, 71, 3-8.

23 M. J. Frisch, G. W. Trucks, H. B. Schlegel, G. E. Scuseria, M. A. Robb, J. R. Cheeseman, G. Scalmani, V. Barone, G. A. Petersson, H. Nakatsuji, X. Li, M. Caricato, A. Marenich, J. Bloino, B. G. Janesko, R. Gomperts, B. Mennucci, H. P. Hratchian, J. V. Ortiz, A. F. Izmaylov, 
J. L. Sonnenberg, D. Williams-Young, F. Ding, F. Lipparini, F. Egidi, J. Goings, B. Peng, A. Petrone, T. Henderson, D. Ranasinghe, V. G. Zakrzewski, J. Gao, N. Rega, G. Zheng, W. Liang, M. Hada, M. Ehara, K. Toyota, R. Fukuda, J. Hasegawa, M. Ishida, T. Nakajima, Y. Honda, O. Kitao, H. Nakai, T. Vreven, K. Throssell, J. A. Montgomery Jr, J. E. Peralta, F. Ogliaro, M. Bearpark, J. J. Heyd, E. Brothers, K. N. Kudin, V. N. Staroverov, T. Keith, R. Kobayashi, J. Normand, K. Raghavachari,
A. Rendell, J. C. Burant, S. S. Iyengar, J. Tomasi, M. Cossi, J. M. Millam, M. Klene, C. Adamo, R. Cammi, J. W. Ochterski, R. L. Martin, K. Morokuma, O. Farkas, J. B. Foresman and D. J. Fox, Gaussian 09, Revision A.02, Gaussian, Inc., Wallingford CT, 2016.

24 A. D. Becke, J. Chem. Phys., 1993, 98, 5648-5652; C. Lee, W. Yang and G. Parr, Phys. Rev. B: Condens. Matter Mater. Phys., 1988, 37, 785-789. 